\title{
Effect of Current Collector and Pyrolysis Temperature on the Electrochemical Performance of Photoresist Derived Carbon Films
}

\author{
M. Kakunuri and C.S. Sharma ${ }^{\mathrm{z}}$ \\ Department of Chemical Engineering, Indian Institute of Technology, Hyderabad, Kandi-502285, Telangana, India
}

SU-8, an epoxy based negative photoresist has been demonstrated as a potential precursor to fabricate thin films and three-dimensional micropatterned arrays in glassy carbon. However, the use of silicon wafer as a substrate cum collector limits their use in real battery devices. In accordance with the commercial lithium ion battery architecture and also owing to enhanced conductivity, we have successfully demonstrated the use of stainless steel (SS) wafer as a current collector to prepare binder free SU-8 derived carbon thin films. Standard carbon microelectromechanical systems (C-MEMS) process parameters were tuned to obtain a uniform, crackfree carbon thin film on SS wafer upon pyrolysis. Further, we varied the final pyrolysis temperature to examine its effect on the microstructure and composition as characterized with X-ray diffraction, Small angle X-ray scattering, Raman spectroscopy and CHNS-O elemental analyzer respectively. The microstructural changes in the carbon films at different pyrolysis temperature were then correlated with their electrochemical performance as investigated using galvanostat charge/discharge experiments, impedance spectroscopy and cyclic voltammetry. Selection of an appropriate current collector and optimizing the pyrolysis temperature yielded excellent cyclic stability and coulombic efficiency with $400 \mathrm{mAh} \mathrm{g}^{-1}$ reversible capacity after 100 cycles, nearly double to as reported in the literature.

(c) The Author(s) 2016. Published by ECS. This is an open access article distributed under the terms of the Creative Commons Attribution Non-Commercial No Derivatives 4.0 License (CC BY-NC-ND, http://creativecommons.org/licenses/by-nc-nd/4.0/), which permits non-commercial reuse, distribution, and reproduction in any medium, provided the original work is not changed in any way and is properly cited. For permission for commercial reuse, please email: oa@electrochem.org. [DOI: 10.1149/2.0011706jss] All rights reserved.

(c) BY-NC-ND

Manuscript submitted September 7, 2016; revised manuscript received October 17, 2016. Published November 29, 2016. This was Paper 1126 presented at the Orlando, Florida, Meeting of the Society, May 11-15, 2014. This paper is part of the JSS Focus Issue on Nanocarbons - In Memory of Sir Harry Kroto.

Carbon is one of the most commonly used anode material used in commercial rechargeable lithium (Li) ion batteries. Based on microstructure and their behavior on heat-treatment, carbonaceous materials can be classified as graphite (highly crystalline), graphitizable soft carbons and non-graphitizable hard carbons. ${ }^{1}$ Among the various carbonaceous materials, graphite materials of different grade have been studied extensively with their reported Li-ion intercalation capacities in the range of $215-370 \mathrm{mAh} \mathrm{g}^{-1}$ which is closer to theoretical capacity of graphite $\left(372 \mathrm{mAh} \mathrm{g}^{-1}\right) .^{2-5}$ In literature, hard carbons have been prepared by pyrolyzing different precursor materials like cotton wool, rice husk, tea leaves, isotropic pitches, epoxy novolac resins, and various other polymers. ${ }^{6-11}$ These hard carbons show much higher reversible capacity $\left(400-700 \mathrm{mAh} \mathrm{g}^{-1}\right)$ than that of graphite $\left(372 \mathrm{mAh} \mathrm{g}^{-1}\right)$. However, large irreversible capacity, average cyclic stability and hysteresis during charging and discharging for hard carbons limit their use in commercial lithium-ion batteries to secondary choice after graphitic carbons. ${ }^{12}$ Adsorption of lithium ions on the surface of the nanopores formed by random arrangement of small graphene sheets with minimal lamellar stacking like "house of cards" (Figure S1), doping of lithium at the edges of small crystallites and binding of one lithium atom with one hydrogen atom on average is known to be accountable for this higher capacity., ${ }^{9-13}$ Along with these reasons, hydroxyl, carboxyl functional groups and moisture content which is very reactive to Li metal also play an important role on electrochemical performance of hard carbon materials. ${ }^{16-18}$ However, the main disadvantage of using hard carbons as anode material for Li-ion battery is their higher initial irreversible capacity. The electrochemical performance of these hard carbons depends on physiochemical properties such as crystallinity, micropore radius and lithium reactive functional groups on the surface of an electrode, which varies with the heat-treatment temperature. Although crystallinity of hard carbons increases with increasing heat-treatment temperature, it is insignificant when compared to graphitizable carbons. ${ }^{1,17,19,20} \mathrm{Mi}$ cropore size increases upon increasing heat-treatment temperature by

${ }^{\mathrm{z} E-m a i l: ~ c s s h a r m a @ i i t h . a c . i n ~}$ aligning neighboring graphene layers as they become mobile at higher temperatures. ${ }^{19}$

Sputtering and spin coating of polymer precursor followed by pyrolysis techniques were widely used for fabricating carbon thin films. ${ }^{21-25}$ Compared to non-photosensitive polymer based and sputtered based techniques, use of photoresist as a precursor allows us to fabricate three dimensional micro-patterned carbon electrodes. Micropatterning of electrode enhances the lithium ion intercalation by minimizing the lithium ion transport distance (diffusion length) and increased surface area. In this work, we choose SU-8, an epoxy based negative photoresist as a precursor to fabricate thin carbon thin films. SU-8 derived carbon is glassy in nature (hard carbon) and contains both graphitic and amorphous zones. ${ }^{26}$ In a typical C-MEMS process, patterned or non-patterned (planar) $\mathrm{C}$ films are conventionally fabricated by UV lithography followed by pyrolysis. Most commonly used substrate in C-MEMS process is silicon wafer due to its low thermal expansion during pyrolysis and minimal surface roughness. However, its low electronic conductivity compared to commonly used current collectors ( $\mathrm{SS}$ foil and $\mathrm{Cu}$ foil) discourages its use as a current collector for electrode preparation in real battery prototypes. Madou et al. reported the reversible capacity of SU-8 derived thin C film prepared on Si wafer as $220 \mathrm{mAh} \mathrm{g}^{-1}$ which was significantly less than that of graphite $\left(372 \mathrm{mAh} \mathrm{g}^{-1}\right)$ and other hard carbon materials. ${ }^{27,28}$ However, owing to its ability to fabricate high aspect ratio 3D micropost arrays in carbon make it suitable to achieve higher specific capacity as compared to thin film architecture.

To investigate the effect of current collector, we consider the use of stainless steel (SS) wafer as a substrate to prepare C films. The selection of SS wafer as a substrate is more apt as the same is used in the commercial Li-ion battery. ${ }^{29}$ Later we have varied the pyrolysis temperature between $973 \mathrm{~K}$ and $1273 \mathrm{~K}$ with an interval of $100 \mathrm{~K}$ to investigate the effect of pyrolysis temperature on the crystalline structure and hydrogen content of the hard C films prepared from the SU-8 through C-MEMS process. Further, this change in the microstructure of thin $\mathrm{C}$ films and electronic conductivity of the current collector has been correlated to their electrochemical properties in terms of lithium ion intercalation. 


\section{Experimental}

Preparation of $\boldsymbol{C}$ films.-SU-8 2005 (Microchem Corp., MA) was spin coated in a yellow room at $3000 \mathrm{rpm}$ for $30 \mathrm{~s}$ on single side polished SS substrates (MTI Corp., USA) dehydrated at 423 $\mathrm{K}$. We have optimized various process conditions such as pre-baking, post-baking, UV exposure dose and hard baking. Pre-baking and postbaking were carried out for 90 and 270 s respectively rather than 120 and $300 \mathrm{~s}$ at $368 \mathrm{~K}$ as reported in standard data sheets for $5 \mu \mathrm{m}$ thick film when $\mathrm{Si}$ wafer is used as a substrate. This reduction in pre- and post-bake time for better adhesion can be attributed to the higher thermal conductivity of SS wafer than Si wafer, which in turn transfers the heat quickly and helps in rapid evaporation of solvent. UV Exposure energy was increased to 1.5 times than for that of Si wafer due to its higher refractive index. Finally, hard bake was carried out at $423 \mathrm{~K}$ for $10 \mathrm{~min}$ with slow heating rate of $3 \mathrm{~K} \mathrm{~min}^{-1}$ to remove the internal stresses. By tuning these parameters we were able to successfully fabricate crosslinked SU-8 films over SS wafer without developing any cracks.

As-prepared crosslinked SU-8 films were then carbonized at various temperature from $973 \mathrm{~K}$ to $1273 \mathrm{~K}$ with the interval of $100 \mathrm{~K}$ in the $\mathrm{N}_{2}$ atmosphere using two step pyrolysis in alumina tube furnace (Nabertherm $\mathrm{GmbH}$ ). The sample in the furnace tube was initially purged with $100 \mathrm{lph} \mathrm{N}_{2}$ flow for 20 mins. After initial purging, $\mathrm{N}_{2}$ flow rate was maintained constantly at $30 \mathrm{lph}$ throughout the process. Temperature was initially ramped to $623 \mathrm{~K}$ at $2 \mathrm{~K} \mathrm{~min}^{-1}$, and dwelled for $20 \mathrm{~min}$. These samples were further ramped to desired temperature at $5 \mathrm{~K} \mathrm{~min}^{-1}$ and dwelled for 1 hour. Then samples were allowed to cool in the presence of $\mathrm{N}_{2}$ atmosphere.

Structural characterization.-We structurally characterized as obtained C films pyrolyzed at different temperatures by X-Ray Diffraction (XRD) pattern and Raman spectroscopy. XRD patterns were recorded on PANalytical X-ray diffractometer (Model: X'Pert $\mathrm{PRO}$ ) with $\mathrm{CuK} \alpha$ radiation source, at an accelerating voltage of $40 \mathrm{~V}$ and $30 \mathrm{~mA}$ current over a $2 \theta$ range from 10 to $30^{\circ}$. Raman spectrum was recorded with a $532 \mathrm{~nm}$ laser using Bruker Raman microscope spectrometer (Model: Senterra). CHNS-O organic elemental analyzer (Thermo Scientific) was used to measure hydrogen, carbon and nitrogen content in C films. Layer of carbon film over SS substrate from two samples were carefully scratched to obtain C film of weight 3-5 $\mathrm{mg}$. Thus obtained carbon samples were filled into silver tins and introduced into CHNS-O combustion chamber for analysis. Small angle X-ray scattering (SAXS) patterns were recorded on point collimation Anton-Paar system (SAXess) with $\mathrm{CuK} \alpha$ radiation $(0.154 \mathrm{~nm})$ under vacuum to estimate the micropore radius. Scratched $C$ film sandwiched between krypton foil was used for measurement. As krypton foil is X-ray transparent, scattering recorded will only correspond to the $\mathrm{C}$ film. High resolution micrographs were recorded with transmission electron microscopy (HRTEM, FEI Tecnai G2S-Twin) operated at $200 \mathrm{kV}$.

Electrochemical characterization.-For electrochemical testing, swagelok cell assembly was used to fabricate half-cell as shown in Figure S2. C films on SS wafer were used as working electrode while, lithium foil (99.9\% pure, Sigma Aldrich) was used as reference electrode. Glass microfiber filter (Whatman Filters) sprayed with electrolyte $\left(1 \mathrm{M}\right.$ solution of $\mathrm{LiPF}_{6}$ in a $1: 1 \mathrm{v} / \mathrm{v}$ mixture of ethylene carbonate and diethyl carbonate) was used as an ionic conductive separator between working and counter electrode. Electrochemical performance of packed half-cells were investigated using galvanostat potentiostat (Biologic Instruments, Model: VSP). All galvanostatic charge-discharge experiments were carried out at room temperature with constant current corresponding to $0.1 \mathrm{C}$ rate $\left(37.2 \mathrm{~mA} \mathrm{~g}^{-1}\right)$ for graphite.

\section{Results and Discussion}

Effect of current collector on the electrochemical performance.-C films show typical hard carbon charge-discharge profiles. As shown in Figure 1 initial discharge capacity was found to be very high compared to subsequent cycles. Reversible specific lithium intercalation capacity of C film over SS wafer was found to be higher than that of theoretical capacity of graphite $\left(\sim 400 \mathrm{mAh} \mathrm{g}^{-1}\right.$ vs. $372 \mathrm{mAh} \mathrm{g}^{-1}$ for graphite) and capacity fade in charge capacity was almost insignificant ( $341 \mathrm{mAh} \mathrm{g}^{-1}$ to $340 \mathrm{mAh} \mathrm{g}^{-1}$ ) during the cycling as shown in Figure 1a. Moreover, as compared to reported values of reversible capacity of $\mathrm{C}$ film $\left.(\sim 220 \mathrm{mAh} \mathrm{g})^{-1}\right)^{27,28}$ on a silicon wafer, it was nearly double. The enhancement of reversible capacity and cyclic stability may be attributed to disordered structure in these $\mathrm{C}$ film as similar to hard carbons and also possibly due to lower resistivity of SS wafer used as a substrate. To see the effect of electronic conductivity on the internal resistances we have used the impedance spectroscopy. Impedance measurements before and after cycling as shown in Figure 2 were done under ac amplitude of $10 \mathrm{mV}$ over the frequency range of $10 \mathrm{mHz}-100 \mathrm{kHz}$ before, after 10 and 100 cycles of charge-discharge. Depressed semi-circle in high-frequency range is ascribed to charge transfer resistance and solution resistance and positive sloped straight line in low-frequency region is ascribed to lithium diffusion in electrode material. ${ }^{30}$ The charge transfer resistance before and after cycling was found to be $17.1 \Omega$ and $54 \Omega$ respectively. The increase in charge transfer resistance is due to formation of passivation layer on $\mathrm{C}$ film and volume expansions during charge-discharge. These results further
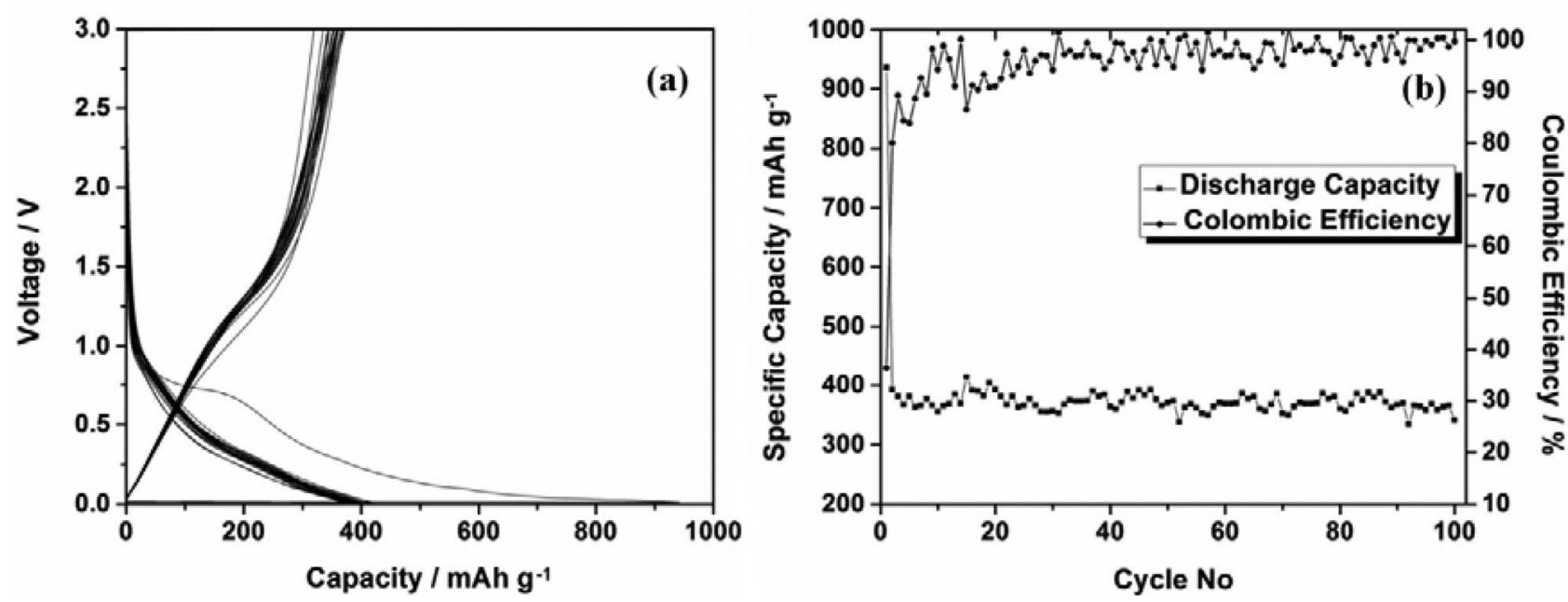

Figure 1. (a) Charge-discharge profile and (b) Cyclic performance of $\mathrm{C}$ film pyrolyzed at $1173 \mathrm{~K}$. 


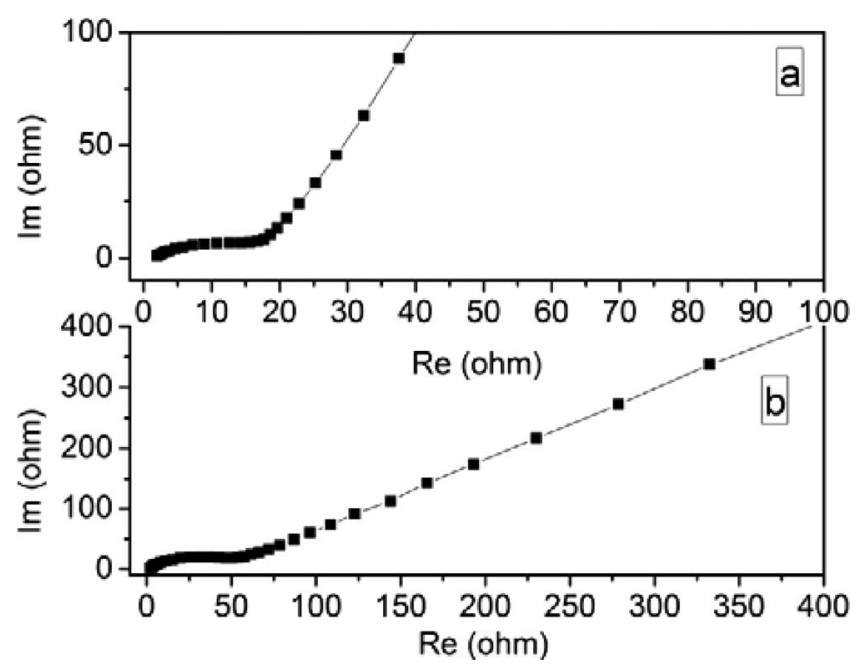

Figure 2. Nyquist plot for $\mathrm{C}$ film pyrolyzed at $1173 \mathrm{~K}$ (a) before and (b) after cycling.

supports the higher reversible capacity values as obtained in this work compared to reported values ${ }^{13-15}$ for $\mathrm{C}$ film on a silicon wafer. For $\mathrm{C}$ film on a silicon wafer, charge transfer resistance reported were significantly higher than the charge transfer resistance values for the same C film over SS wafer. ${ }^{27}$ Additionally the electrolyte resistance was also more than one order of magnitude larger as compared to the present work designed architecture (SU-8 photoresist derived $\mathrm{C}$ film on SS substrate as anode).

Effect of pyrolysis temperature on physical and chemical properties of carbon thin films.-Crystallinity.-Figure 3 shows the XRD patterns for $\mathrm{C}$ films pyrolyzed at various temperatures. Broad Bragg peaks at $2 \theta=26^{\circ}$ at $\left(\begin{array}{lll}0 & 0 & 2\end{array}\right)$ reflection may be attributed to poorly arranged small graphene layers arranged like house of cards. ${ }^{31}$ As we observe that there is no significant change in either peak position or broadness of peak, it suggests that with change in pyrolysis temperature from $973 \mathrm{~K}$ to $1273 \mathrm{~K}$, crystallite thickness of these $\mathrm{C}$ films remain unchanged. Figure 4a shows Raman spectrum of these $\mathrm{C}$ films. For all the samples, we can clearly observe the two characteristic peaks at $1329 \mathrm{~cm}^{-1}$ and $1592 \mathrm{~cm}^{-1}$ associated with D and $\mathrm{G}$ band respectively. $\mathrm{D}$ band is associated with presence of dangling bonds while $\mathrm{G}$ band reveals the graphitic arrangement of layers in the carbon. We did not observe any peak shift for all four samples. However, to extract the information further from Raman spectroscopy, we calculated the ratio of

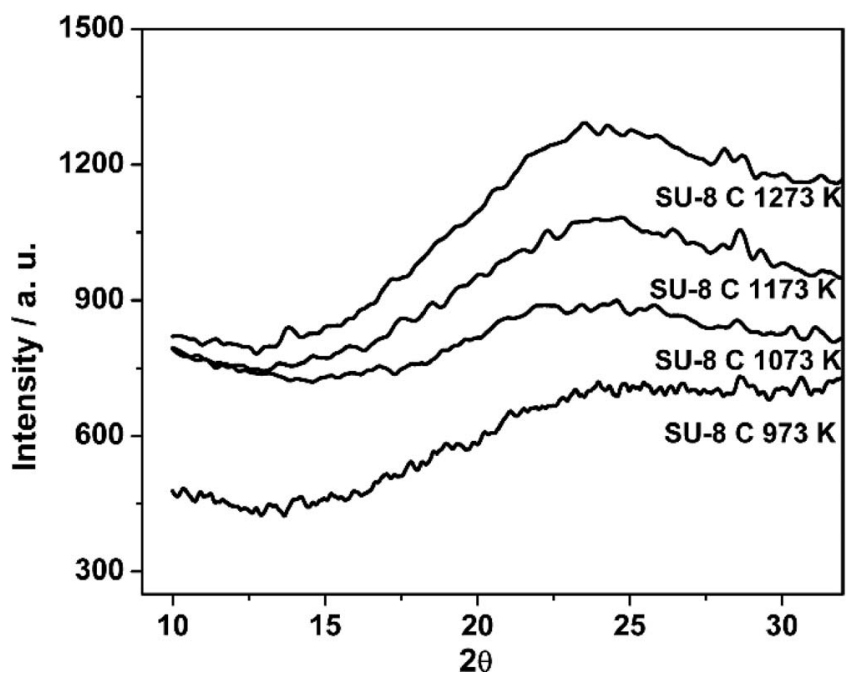

Figure 3. XRD spectrum of $\mathrm{C}$ films pyrolyzed at different temperatures.

G-peak and D-peak intensities which is ascribed to degree of disorder and in-planer vibrations of hexagonal network. ${ }^{32}$ Crystallite domain size $\mathrm{L}_{\mathrm{a}}$ is also calculated using empirical formula $\mathrm{L}_{\mathrm{a}}=4.4\left(\mathrm{I}_{\mathrm{G}} / \mathrm{I}_{\mathrm{D}}\right){ }^{32}$ Figure $4 \mathrm{~b}$ shows effect of pyrolysis temperature on crystallite domain size expressed as in-planar width $\left(\mathrm{L}_{\mathrm{a}}\right)$ and $\mathrm{I}_{\mathrm{D}} / \mathrm{I}_{\mathrm{G}}$ ratio of $\mathrm{C}$ films pyrolyzed at different temperatures. In-planar width $\left(\mathrm{L}_{\mathrm{a}}\right)$ is width of crystallite in the plane of graphene layer (a-axis). In agreement with XRD studies, increase in crystallite domain size was observed to be minimal from 2.0 to $3.4 \mathrm{~nm}$ with increasing temperatures from $973 \mathrm{~K}$ to $1273 \mathrm{~K}$ respectively. Similarly, $\mathrm{I}_{\mathrm{D}} / \mathrm{I}_{\mathrm{G}}$ ratio decreased from 2.19 to 1.3 which signifies the partial increase in crystallinity with increased temperature, however, the increase is not very significant. TEM image (Figure S3) of C films obtained at $1273 \mathrm{~K}$ shows the randomly arranged graphene layers locally in a very small vicinity which further supports XRD and Raman spectroscopy findings.

Further, SAXS curves for carbon thin films prepared at different temperatures are summarized as Figure 5a. Intensity of the transmitted beam of X-rays with $0.154 \mathrm{~nm}$ wavelength was recorded on two-dimensional (2D) image plate versus scattering vector $\mathrm{q}(\mathrm{q}=$ $4 \pi \sin \theta / \lambda)$. Radius of gyration $\left(\mathrm{R}_{\mathrm{g}}\right)$ was calculated from the Guinier approximation using SAXS quant software using these scattering curve and is summarized in Figure $5 \mathrm{~b}$. The value of $\mathrm{R}_{\mathrm{g}}$ increased from 1.13 to $1.72 \mathrm{~nm}$ with increase in temperature from 973 to $1273 \mathrm{~K}$. This increase may be due to the alignment of small graphene layers with the neighboring layers as temperature increases. ${ }^{19}$ Alignment at higher
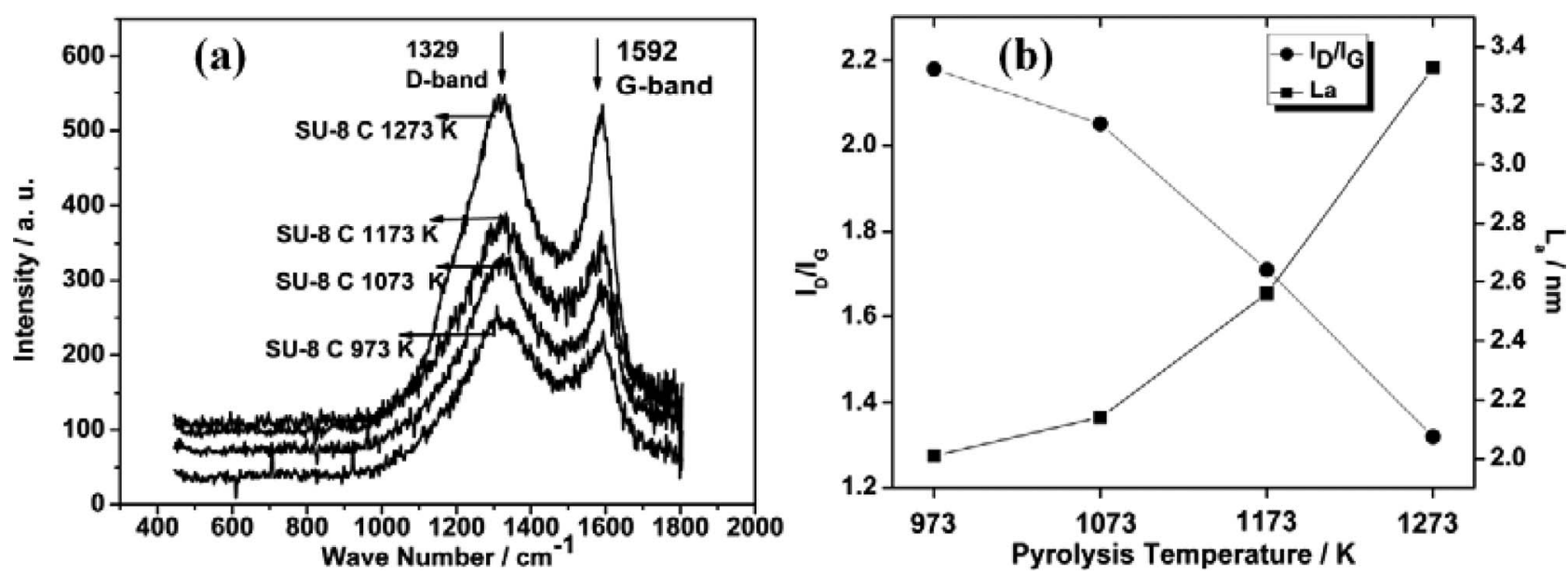

Figure 4. (a) Raman spectrum of C films pyrolyzed at different temperatures and (b) Effect of pyrolysis temperature on in-planer graphite crystallite width. 

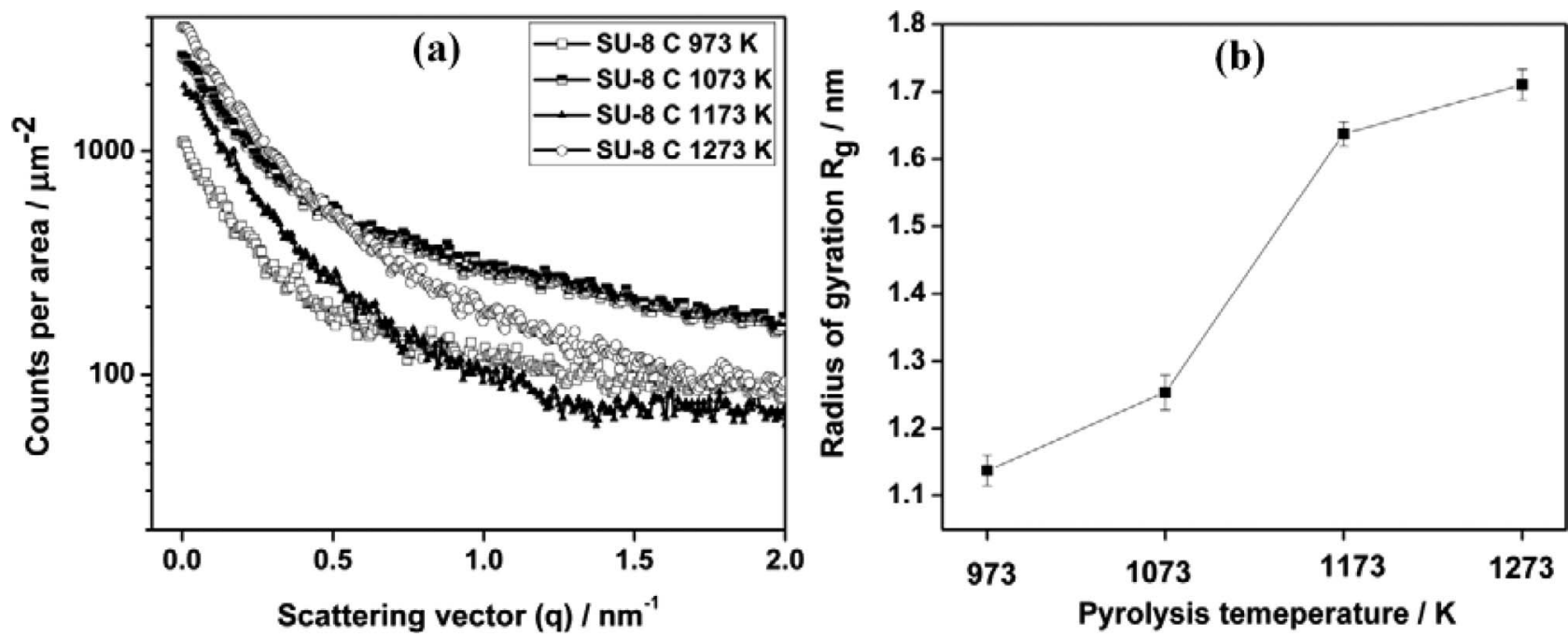

Figure 5. (a) SAXS curves for C films pyrolyzed between 973 and $1273 \mathrm{~K}$ and (b) Effect of pyrolysis temperature on radius of gyration.

temperatures minimizes the number of micropores and increases the radius of micropores which further decreases the surface area of the sample.

$\mathrm{H} / \mathrm{C}$ ratio.-As reported in the literature, elemental ratio of $\mathrm{H} / \mathrm{C}$ also plays an important role in lithium ion intercalation as hydrogen also reacts with lithium during the discharge. ${ }^{16,17} \mathrm{We}$, therefore, carried out the elemental analysis for $\mathrm{C}$ films and calculated $\mathrm{H} / \mathrm{C}$ atomic ratio with change in temperature (Figure 6). Weight percentages of carbon, hydrogen, nitrogen and oxygen were given in Table S1. H/C atomic ratio (molar ratio) was calculated by multiplying weight ratio of $\mathrm{H} / \mathrm{C}$ with 12 (reciprocal of molecular weight). Weight percentage of carbon increased from $54.1 \%$ to $88.7 \%$ with an increase in temperature while the amount of other elements like hydrogen, oxygen and nitrogen was found to be decreasing. Therefore $\mathrm{H} / \mathrm{C}$ ratio decreased from 0.66 at $973 \mathrm{~K}$ to 0.21 at $1273 \mathrm{~K}$. The change in hydrogen content (or $\mathrm{H} / \mathrm{C}$ ratio) further affected the lithium ion intercalation capacity for these $\mathrm{C}$ films as discussed further.

Effect of pyrolysis temperature on electrochemical performance.-Cyclic voltammetry.-Cyclic voltammetry of half-cell was recorded at $0.1 \mathrm{mV} \mathrm{s}^{-1}$ in the voltage range of $0-3 \mathrm{~V}$. Figure 7 showing the cyclic voltammogram of $\mathrm{C}$ film pyrolyzed at $1173 \mathrm{~K}$ with two redox peaks at $0.5 \mathrm{~V}$ and $0 \mathrm{~V}$. Similar behavior was observed for the $\mathrm{C}$ films pyrolyzed at other temperatures. First

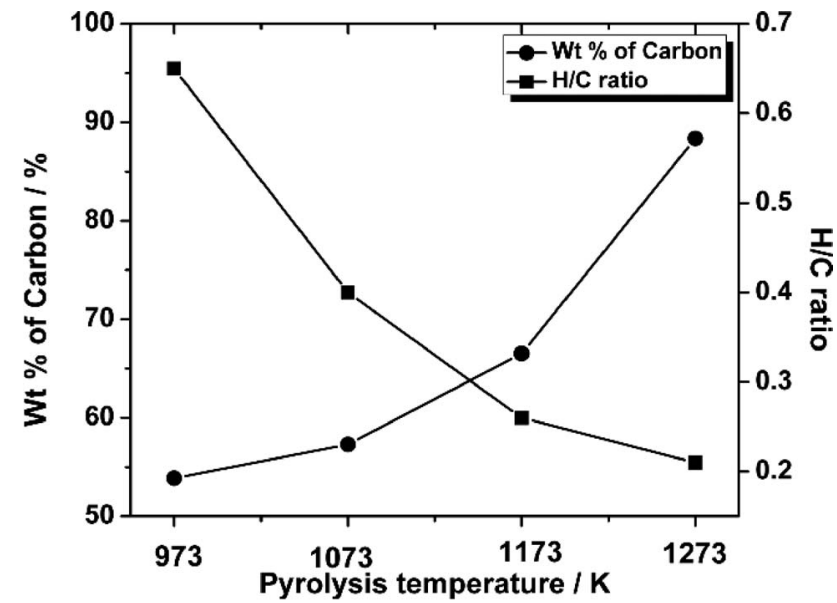

Figure 6. Effect of pyrolysis temperature on carbon content and H/C ratio. broad peak in first cycle about $0.5 \mathrm{~V}$ corresponds to deposition of SEI layer on the carbon electrode due to decomposition of electrolyte to form insoluble lithium oxides, carbonates and halides. ${ }^{33,34}$ Whereas second redox peak at nearly $0 \mathrm{~V}$ corresponds to doping of lithium on the surface of clusters, trapping of lithium ions inside nanopores and lithium ion intercalation in between graphene layers of small size crystallites. $^{10}$

Irreversible capacity.-Figure 8a summarizes the effect of pyrolysis temperature on initial discharge capacity and irreversible capacity. An initial discharge capacity (lithium insertion) of $1531 \mathrm{mAh} \mathrm{g}^{-1}$ was observed for C film pyrolyzed at $973 \mathrm{~K}$ which was reduced to $793 \mathrm{mAh}$ $\mathrm{g}^{-1}$ for the $\mathrm{C}$ film pyrolyzed at highest temperature $(1273 \mathrm{~K})$. Further, irreversible capacity losses were also reduced from $937 \mathrm{mAh} \mathrm{g}^{-1}$ to $464 \mathrm{mAh} \mathrm{g}^{-1}$ with the increase in pyrolysis temperature from 973 to $1273 \mathrm{~K}$. As we observed earlier that increase in pyrolysis temperature decreased the hydrogen content and increased crystallinity. This may reduce the lithium binding to hydrogen and lithium consumption in SEI formation during the first discharge cycle and thus decrease in irreversible capacity losses as measured.

Cyclic performance of prepared carbon anode materials.-Figure $8 \mathrm{~b}$ shows the reversible capacity of $\mathrm{C}$ films pyrolyzed at different

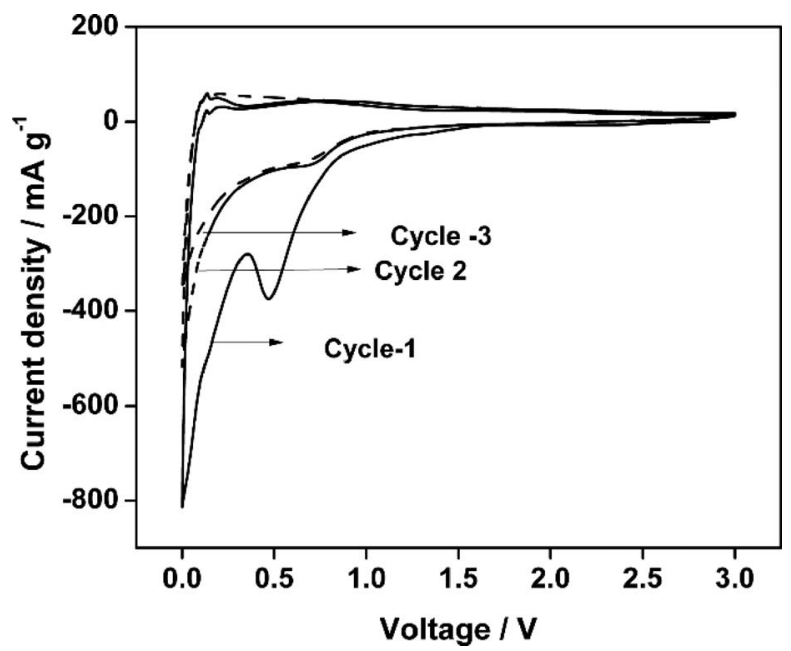

Figure 7. Cyclic voltammogram of C film pyrolyzed at $1173 \mathrm{~K}$. 

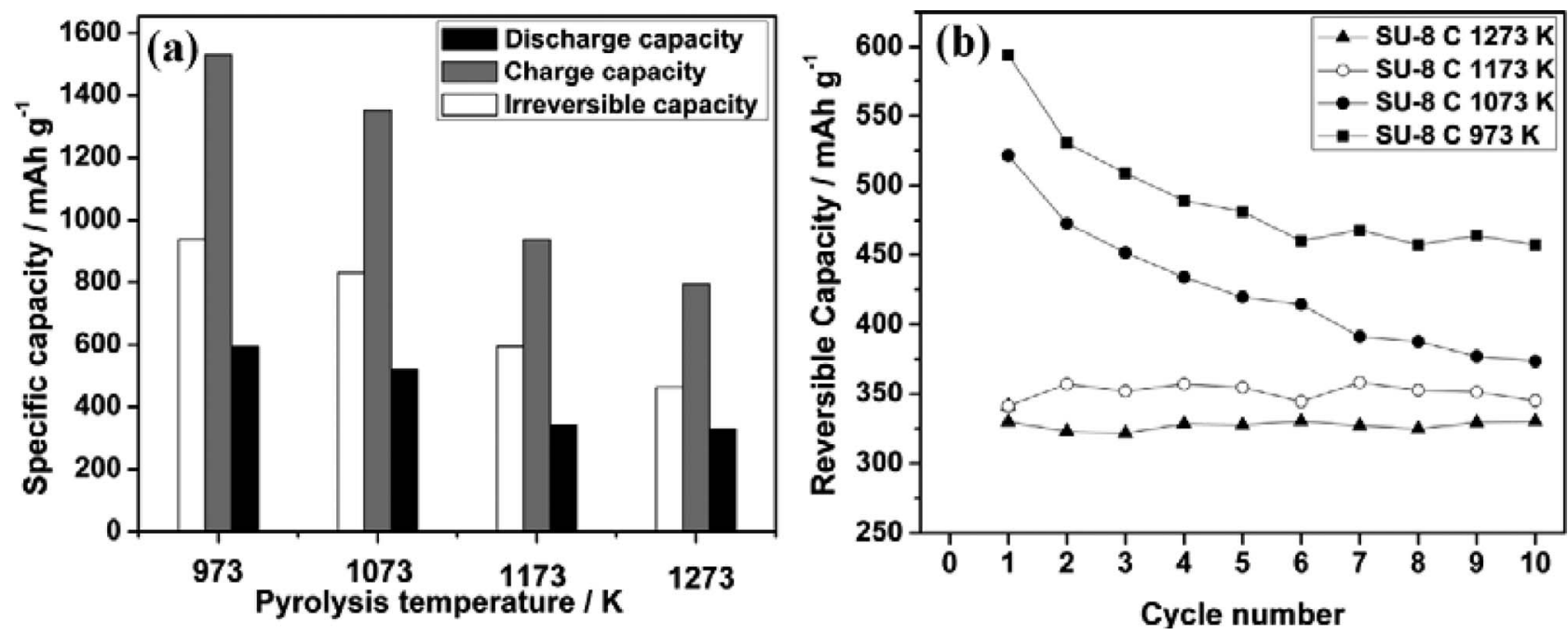

Figure 8. Effect of pyrolysis temperature on (a) initial discharge capacity and irreversible capacity and (b) Cyclic performance.

temperatures for initial ten cycles. Although C films prepared at 973 $\mathrm{K}$ and $1073 \mathrm{~K}$ shows higher reversible capacity but at the same time, capacity fade is significant when compared to $\mathrm{C}$ films pyrolyzed at $1173 \mathrm{~K}$ and $1273 \mathrm{~K}$ respectively. Capacity fade for $\mathrm{C}$ films pyrolyzed at $973 \mathrm{~K}$ and $1073 \mathrm{~K}$ after 10 cycles was found to be $23 \%$ (594$\left.457 \mathrm{mAh} \mathrm{g}^{-1}\right)$ and $28 \%\left(521-373 \mathrm{mAh} \mathrm{g}^{-1}\right)$ respectively whereas $\mathrm{C}$ films pyrolyzed at $1173 \mathrm{~K}$ and $1273 \mathrm{~K}$ showed almost no fade. Reversible capacity for these $\mathrm{C}$ films was found to be stable at about 385 and $330 \mathrm{mAh} \mathrm{g}^{-1}$ at $1173 \mathrm{~K}$ and $1273 \mathrm{~K}$ respectively. This may be due to decrease in hydrogen content and also the surface area with increased temperature, which might have resulted in minimizing the lithium consumption during SEI formation and thus reduction in charge transfer resistance.

Impedance spectroscopy.-Impedance spectroscopy was performed for batteries before beginning charge-discharge experiment and after ten charge-discharge cycles to investigate change in internal resistance. Nyquist plots for the four samples before and after cycling were shown in Figures 9a and 9b. At open circuit voltage before charge-discharge experiment $\mathrm{C}$ films pyrolyzed at different temperatures showed charge transfer resistance about $12 \Omega$, but after cycling (10 charge-discharge cycles) charge transfer resistance of C films pyrolyzed at 973 and $1073 \mathrm{~K}$ was found to be $210 \Omega$ and

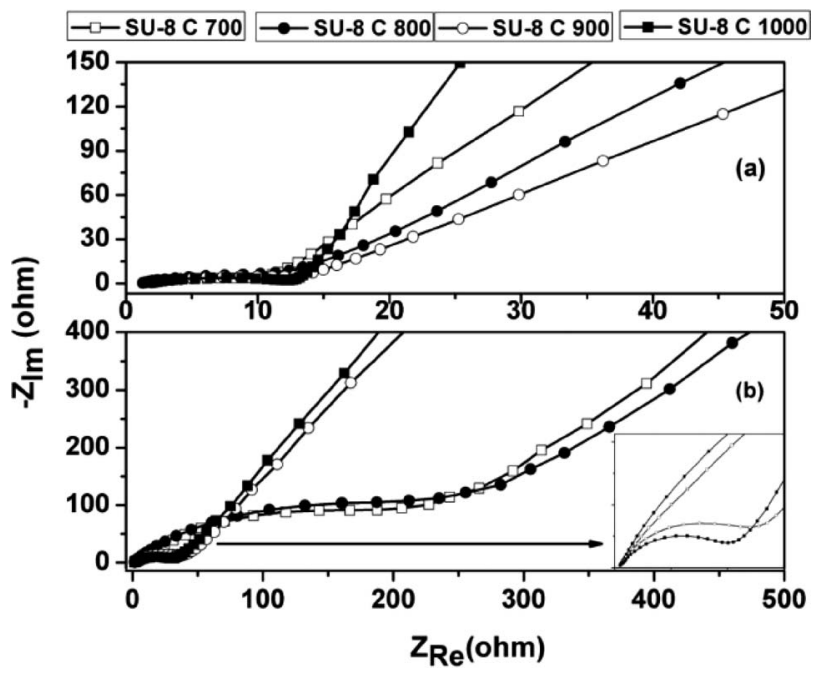

Figure 9. Nyquist plots for $\mathrm{C}$ films electrodes (a) before and (b) after cycling.
$230 \Omega$ respectively. These values were much higher when compared to samples pyrolyzed at $1173 \Omega$ and $1273 \mathrm{~K}$ with charge transfer resistances $39 \Omega$ and $31 \Omega$ respectively. This may be attributed to thicker SEI layer formation over these electrodes which is also reflected in terms of high irreversible capacity and capacity fade for the $\mathrm{C}$ films pyrolyzed at lower temperature as discussed earlier.

\section{Conclusions}

In this contribution, we have successfully fabricated thin $\mathrm{C}$ films by pyrolyzing the negative photoresist, SU-8 at different temperatures on SS wafer used as a substrate. The selection of SS wafer as a substrate was found to play a major role in determining their electrochemical properties. Further, $\mathrm{C}$ films as fabricated can be categorized as hard carbon owing to their disorderness as examined by XRD and Raman spectroscopy and further supported by TEM. This disordered structure plays an important role for higher reversible capacity for these $\mathrm{C}$ films by providing additional sites for lithium adsorption however with increased crystallinity at higher temperature, capacity fade improved significantly. Further, we observed that as temperature increased from 973 to $1273 \mathrm{~K}$, carbon yield increased and $\mathrm{H} / \mathrm{C}$ atomic ratio decreased. Initial discharge capacity and reversible capacity decreases with increasing temperature. This also influenced positively on electrochemical performance of these $\mathrm{C}$ films pyrolyzed at higher temperatures. In summary, we can conclude that although initial capacity was found to significantly higher for the $\mathrm{C}$ film pyrolyzed at lower temperature ( $973 \mathrm{~K}$ ) but for practical use, long term cyclic stability and coulombic efficiency made the choice for $\mathrm{C}$ films pyrolyzed at higher temperature $(1173 \mathrm{~K})$ obvious. Higher capacity with enhanced coulombic efficiency make $\mathrm{C}$ films on SS wafer provide a better alternative for anode materials in Li-ion battery. Further, patterning of these $\mathrm{C}$ films to yield 3-D carbon structures on SS substrate may be useful to further achieve the high energy density architecture for Lithium ion battery.

\section{Acknowledgment}

We thank Indian Institute of Technology, Hyderabad for providing the necessary research infrastructure. CSS acknowledge the DSTSERB Young Scientist Award for partial financial support. We also acknowledge Sudhakar Yenumala and Suresh Kali for their help in CHNS-O and SAXS analysis respectively. Authors acknowledge University of Hyderabad for TEM analysis. 
2. P. Ridgway, H. Zheng, A. F. Bello, X. Song, S. Xun, J. Chong, and V. Battaglia, J. Electrochem. Soc., 159(5) A520 (2012).

3. H. Huang, W. Liu, X. Huang, L. Chen, E. M. Kelder, and J. Schoonman, Solid State Ionics, 110, 173 (1998).

4. H. Shi, J. Barker, M. Y. Saydi, R. Koksbang, and L. Morris, J. Power Sources, 68 291 (1997).

5. K. Zaghib, G. Nadeau, and K. Kinoshita, J. Electrochem. Soc., 147(6), 2110 (2000)

6. S. Bhardwaj, M. Sharon, T. Ishihara, S. Jayabhaye, R. Afre, T. Soga, and M. Sharon, Carbon Lett., 8, 285 (2007).

7. A. Piotrowska, K. Kierzek, P. Rutkowski, and J. Machnikowski, J. Anal. Appl. Pyrolysis, 102, 1 (2013).

8. E. Peled, V. Eshkenazi, and Y. Rosenberg, J. Power Sources, 76, 153 (1998).

9. T. Zheng, Y. Liu, E. W. Fuller, S. Tseng, U. V. Sacken, and J. R. Dahn, J. Electrochem. Soc., 142, 2581 (1995).

10. I. Mochida, C. Ku, and Y. Korai, Carbon, 39, 399 (2001).

11. G. T. Fey and C. L. Chen, J. Power Sources, 97-98, 47 (2001).

12. M. Endo, C. Kim, K. Nishimura, T. Fujino, and K. Miyashita, Carbon, 38, 183 (2000).

13. Y. Matsumura, S. Wang, T. Kasuh, and T. Maeda, Synth. Met., 71, 1755 (2000).

14. Y. Liu, J. S. Xue, T. Zheng, and J. R. Dahn, Carbon, 34, 193 (1996).

15. K. Sato, M. Noguchi, A. Demachi, N. Oki, and M. Endo, Science, 264, 556 (1994).

16. J. R. Dahn, T. Zheng, Y. Liu, and J. S. Xue, Science, 270, 590 (1995).

17. E. Buiel and J. R. Dahn, Electrochem. Acta, 45, 121 (1999).

18. W. Xing and J. R. Dahn, J. Electrochem. Soc., 144, 1195 (1997)

19. E. Buiel, A. E. George, and J. R. Dahn, J. Electrochem. Soc., 145, 2252 (1998).

20. W. Xing, J. S. Xue, and J. R. Dahn, J. Electrochem. Soc., 143, 3046 (1996).
21. A. Javid, M. Kumar, and J. G. Han, Appl. Surf. Sci., 392, 1062 (2017).

22. A. Javid, M. Kumar, S. Yoon, J. H. Lee,S. Tajima, M. Hori, and J. G. Han, J. Phys. D. Appl. Phys., 49, 264001 (2016).

23. M. Kumar, J. X. Piao, S. B. Jin, J. H. Lee, S. Tajima, M. Hori, and J. G. Han,. Arch. Biochem. Biophys., 605, 41 (2016).

24. M. Daranyi, I. Sarusi, A. Sapi, A. Kukovecz, Z. konya, and A. Erdohelyi, Thin solid films, 520, 57 (2011)

25. A. Javid, M. Kumar, and J. G. Han, RSC Adv., 5, 96360 (2015).

26. A. Mardegan, R. Kamath, S. Sharma, P. Scopece, P. Ugo, and M. Madou, J. Electrochem. Soc., 160, B132 (2013).

27. G. T. Teixidor, R. B. Zaouk, B. Y. Park, and M. Madou, J. Power Sources, 183, 730 (2008).

28. C. Wang, L. Taherabadi, G. Jia, M. Madou, Y. Yeh, and B. Dunn, Electrochem. Solid-State Lett., 7, A435 (2004).

29. Y. Wang, H. Liao, J. Wang, Y. Zhu, and S. Cheng, Int. J. Electrochem. Sci., 8, 4002 (2013).

30. C Wang, A. J. Appleby, and F. E. Little, Electrochem. Acta, 46, 1793 (2001)

31. F. J. Maldonado-Hodar, C. Moreno-Castilla, J. Rivera-Utrilla, Y. Hanzawa, and Y. Yamada, Langmuir, 16, 4367 (2000).

32. J. Schwan, S. Ulrich, V. Batori, H. Ehrhardt, and S. R. P. Silva, J. Appl. Phys., 80, 440 (1996).

33. S. Zhang, M. S. Ding, K. Xu, J. Allen, and T. R. Jow, Electrochem. Solid-State Lett., 12, A206 (2001)

34. F. Wang, J. Graetz, M. S. Moreno, C. Ma, L. Wu, V. Volkov, and Y. Zhu, ACS NANO, 51190 (2011). 